\title{
Design of a Circularly Polarized Antenna at 2.45GHz with Harmonic Suppression for Material Characterization
}

\author{
Maizatul Alice Meor Said ${ }^{1}$, Mohamad Harris Misran², Zahriladha Zakaria ${ }^{3}$, Muhamad Fakhrur Razy \\ Mohd Zin ${ }^{4}$, Lailatul Niza Muhammad ${ }^{5}$ \\ ${ }^{1,2}$ Centre for Telecommunication Research \& Innovation (CeTRI), Faculty of Electronics and Computer \\ Engineering, Universiti Teknikal Malaysia Melaka, Hang Tuah Jaya, 76100 Durian Tunggal, Melaka, Malaysia \\ ${ }^{5}$ Faculty of Electrical \& Electronics Engineering, Universiti Malaysia Pahang, Pekan, Pahang \\ ${ }^{1}$ maizatul@utem.edu.my, ${ }^{2}$ harris@utem.edu.my, ${ }^{3}$ zahriladha@utem.edu.my, ${ }^{4}$ fakhrur.razyy@gmail.com, \\ ${ }^{5}$ lailatul@ump.edu.my
}

\begin{abstract}
Circular polarization is necessary in antenna applications especially for energy harvesting as matching the polarization in both the receiving and transmitting antennas can decrease the transmission losses. To achieve this matching, the transmitter and the receiver should have the same sense of polarization, axial ratio and the same spatial orientation. As the waves in our surroundings could be randomly propagating due to human body or device movements in wireless technologies applications such as RFID, GPS and WLAN, circular polarization comes in handy to reduce the effect of multipath reflections, enhances weather penetration and allows for the mobility of both the transmitter and the receiver. The objective of this paper is to design a circularly polarized microstrip antenna that operates at $2.45 \mathrm{GHz}$ with harmonic suppression for energy harvesting applications. Single feeding technique is used because of its simplicity, cost efficient, easy to fabricate, and compact size. This paper presents a new design of a circularly polarized antenna with harmonic suppression based on a rectangular microstrip patch. Two truncated edges placed on the opposite side of the patch antenna generate circular polarization. The truncation technique is used to be able to split the field into two orthogonal modes with $90^{\circ}$ phase shift of equal magnitude.
\end{abstract}

Key words : Antenna, Conversion Efficiency, Rectenna and Rectifying

\section{INTRODUCTION}

Recently, fast growth of wireless energy harvesting application becomes a major cause for engineers to design the most efficient antenna. The antenna mentioned is a compact, cost effective and lightweight microstrip antenna [1]. That is what it is about in this project, designing new circularly polarized (CP) microstrip antennas that are mostly used in various types of wireless communication system nowadays since it was introduced in 1953 [2]. It is found to be a very necessary consideration in the antenna design industry as it able to put an end to the need of antenna orientation in the plane perpendicular to the propagation direction. Radio signals are tended to be absorbed and reflected based on the material it contacts with. So, with CP antenna, it gives a much more flexibility to the angle between the signals and the antenna resulting the signals always be recognized [3][4]. However, the MSA design need to be change for it to be able to generate the circular polarization [5]. For circular polarization to be generated in microstrip antenna, two modes equal in magnitude and 90 out of phase are required [6]. Researchers has found that designing a microstrip patch antenna with good gain and radiation pattern is a major challenge among engineers [7]. High gain antenna also required in monitoring and control system such as in agricultural [8] and on body applications [9].

The design should be capable to receive RCHP and LHCP simultaneously and also able to filter unwanted harmonic signals. The Computer Simulation Technology (CST) will be used to simulate and optimize the design. Once the best design had been chosen, it will then be fabricated using photo-lithography technique and measured in anechoic chamber or vector network analyzer (VNA). Finally, from the simulation and measurement, the proposed design of the antenna can be verified as a good choice in the future of wireless power transmission (WPT) application in an operating frequency of $2.45 \mathrm{GHz}$.

\section{THE PROPOSED RECTENNA GEOMETRY DESIGN}

The main objective in this project is to design a harmonic suppressed circularly polarized microstrip patch antenna that operates in $2.45 \mathrm{GHz}$ frequency for energy harvesting. Harmonic suppression is a highlight in the design process to increase the efficiency of antenna.

Next, is to analyze an efficient technique to acquire circularly polarized radiation pattern of the antenna. This objective ensures that the antenna emits radiation in circular 
polarization to eliminate the Faraday's Effect that can occur in linear polarization. It is also making the antenna easier to install as its only requirement is to direct it correctly.

Finally, after obtaining a final design of the microstrip patch antenna, the last objective is to fabricate and verified the design in the laboratory. Fabrication of the antenna consist of etching process to print the antenna configuration onto FR-4 board. A measurement process is then will be performed to compare parametric values to the one obtained from simulation.

The main goal of this project is to design a circularly polarized microstrip antenna that operates in $2.45 \mathrm{GHz}$ with harmonic suppression for energy harvesting applications. There are 5 scopes that will be covered during the process. Firstly, is to design the geometry of the antenna to make sure it meets the polarization requirement while applying a harmonic rejection characteristic. The harmonic rejection characteristic is achieved through various techniques. After that, the design will need to be optimized to improve the efficiency, gain and radiating pattern of the antenna. Optimization of the geometry will be perform using CST far-field simulation. Next, the process will be fabrication the microstrip patch antenna by using FR-4 Board with 4.7 dielectric constant and the substrate standard thickness, $\mathrm{h}$ is $1.6 \mathrm{~mm}$. Measure the radiation pattern using Vector Network Analyzer and in an anechoic chamber in the laboratory. Investigate the performance of the antenna in term of return loss values.

\subsection{Advantages And Disadvantages Of Microstrip Antenna}

The microstrip antenna has several advantages that attracts researchers to perform research in order to develop the most efficient design. The main advantage surely be about its flexibility as a low-profile antenna which can confront a planar and nonplanar surface because the shape design fits the needs of modern communication equipment. The microstrip antenna shape flexibility also enables them to be mounted on a rigid surface which makes them mechanically robust. In the other hand, microstrip antennas can be mass produced using simple and cost-efficient modern printed PCB technologies. The use of PCB manufacturing technologies also allows fabrication of the feeding line and matching networks with the antenna structure. From a designer perspective, microstrip antenna presents a wide range of options as they can vary the choice of the substrate, the antenna structure design, type of perturbation and the feeding techniques to achieve the antenna design objective [10].

However, on the lower side of microstrip antennas, they give a narrow impedance bandwidth, lower efficiency compared to other type of antenna, and they can only be used in low power applications. UWB antenna can be achieved using monopolar patch antenna and defected ground structure (DGS) implemented on the antenna ground plane [11][12]. Microstrip antennas also show a poor performance when used in scanning applications. Polarization characteristic produced by a microstrip antenna also shows poor behavior. Furthermore, most microstrip antenna can radiate only in half-space because of the implementation on double sided substrates where one side is used as a ground. The half space radiation will limit their use in some application. The research in microstrip antenna design nowadays mainly focuses on how to overcome these problems [13][14].

\subsection{Microstrip Patch Antenna}

Deschamps is the person who gives the idea of microstrip antenna back in 1953 and was patented 1955 but, it was fabricated about 20 years later during the 1970's when suitable dielectric substrates became available. Since then, microstrip antennas continue to develop increasingly as it adds the option of antenna design and attracts researchers in a wide range of modern microwave systems. The antenna uses and applications was the main effect of its fast growth industry and it defines of the development and improvement of its characteristics through a continuous research effort [6][10]. In a basic communication system, the major role in elevating the system performance is to increase the gain of antennas used for transmission and reception.

A microstrip patch antenna (MSA) is a lightweight and cost-effective type of antenna that is increasingly useful especially in mobile phone market as they can be fabricated easily onto a circuit board. Basically, an MSA is made of copper printed on a substrate with a certain dielectric constant, $\varepsilon_{\mathrm{r}}$ that is fed by a transmission line against a ground. Referring to Figure 1, the basic geometry of the patch antenna consists of length, $\mathrm{L}$ and width, $\mathrm{W}$, that sits on a dielectric substrate of thickness, $h$.

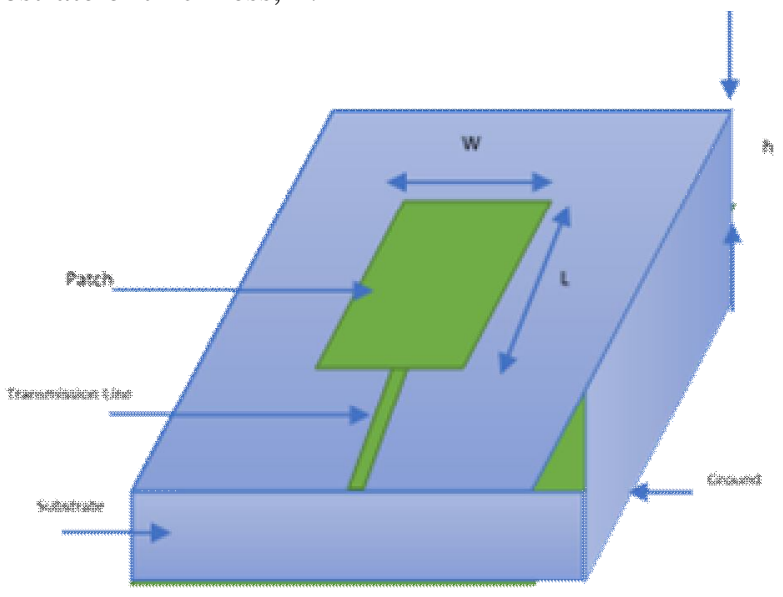

Figure 1: Basic geometry of MSA 


\subsection{Substrate}

A substrate is the dielectric layer placed between the patch and the ground. There are a lot of substrate material and specifications to choose from according to the antenna requirement. There are two factors specifying dielectric substrate which is the substrate height that available from $0.003 \lambda \mathrm{o}$ to $0.05 \lambda_{\mathrm{o}}$ and dielectric constant from 2.2 to 12 depends on the material used. The higher the value of the dielectric constant $\varepsilon_{\mathrm{r}}$, the smaller the size of the antenna. It is preferred to choose a substrate that are thick with low dielectric constant as it is suitable for enhancement of bandwidth, efficiency and radiation in space. An FR-4 type of substrate is one of other suitable choices in this project as it is cost efficient and with $2.45 \mathrm{GHz}$ resonating frequency, the antenna will take a compact size to produce. Figure 2 shows the FR-4 layers.

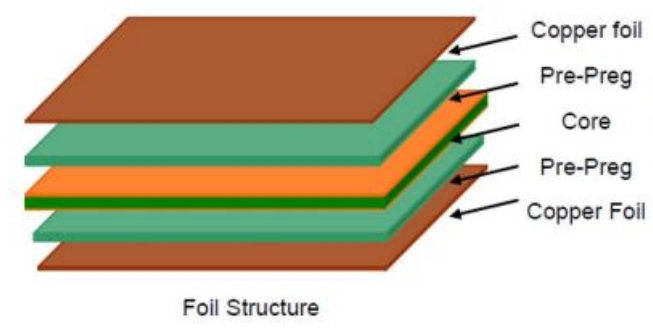

Figure 0: FR-4 layers

\subsection{Design Specification}

The proposed antenna must be able to meet the following specifications; as shown in Table 1 to have an efficient antenna for energy harvesting applications.

Table 1: Design Specifications of MSA

\begin{tabular}{|l|l|}
\hline Parameters & Specification \\
\hline Operating frequency $(\mathrm{GHz})$ & 2.45 \\
\hline Gain $(\mathrm{dB})$ & $>3$ \\
\hline Return Loss $(\mathrm{dB})$ & $>-10$ \\
\hline Axial Ratio & 1 \\
\hline Harmonic Suppression & Up to $4^{\text {th }}$ Order \\
\hline
\end{tabular}

\section{RESULT ANALYSIS OF THE PROPOSED RECTENNA}

The antenna is made of a rectangular patch and a defective ground structure consists of a combination of ring slot, two vertical slots, inverted L-Shaped slot bounded to the ring slot and at the edges of the ground. These techniques enable the antenna to operate at $2.45 \mathrm{GHz}$ and circularly polarized as well as suppressing higher order harmonics.

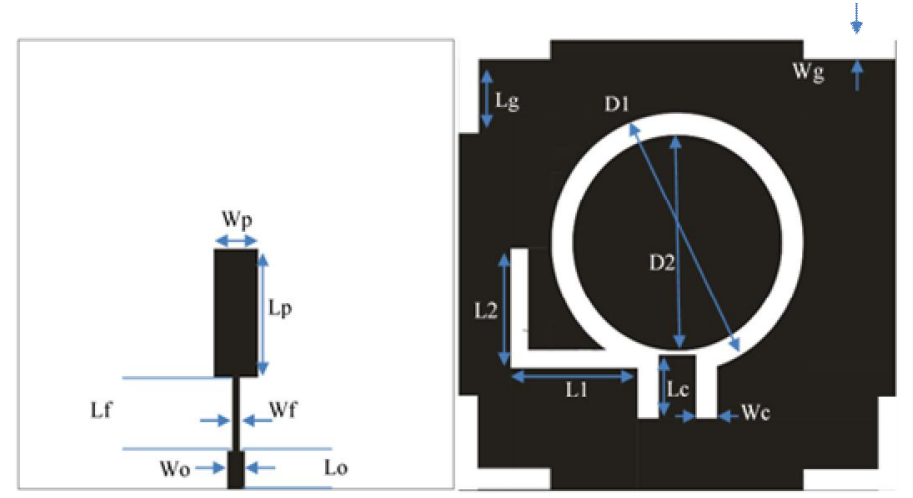

Figure 3: Dimension of fabricated antenna

Figure 3 shows the detailed configurations and dimension of the best simulated antenna that have been fabricated to proceed to far field measurement. Here, the antenna with dimension of $60 \times 58 \mathrm{~mm}$ is been fabricated using a $1.6 \mathrm{~mm}$ thick FR-4 substrate with 4.4 dielectric constant and tangent loss of 0.02 .

The diameter of the ring D2 to D1 is from $30 \mathrm{~mm}$ to $34 \mathrm{~mm}$ giving the width of the ring slot equals to $2 \mathrm{~mm}$. The inverted $\mathrm{L}$-Shaped slot is $2 \mathrm{~mm}$ wide and the total length of $\mathrm{L} 1+\mathrm{L} 2$ is based on the quarter wavelength of the antenna operating frequency which is in this case would be $2.45 \mathrm{GHz}$ and giving the total length $\mathrm{L} 1+\mathrm{L} 2=34.75 \mathrm{~mm}$. This L-Shaped slot will help the antenna to excite CP radiation and it is L-Shaped instead of straight horizontal slot is to reduce the width of the overall antenna. The patch of the antenna is made up of two patches located at the center and on the feedline of the antenna that is connected by a transformer. The center patch which is the main patch has a dimension of $18 \times 6 \mathrm{~mm}$ while the bottom one has $5 \times 2.35 \mathrm{~mm}$ dimension and the transformer is $10 \times 0.9 \mathrm{~mm}$. Table 2 summarize the antenna parameters.

Table 2: Parameters of fabricated antenna

\begin{tabular}{|c|c|}
\hline Design Parameter & Value (mm) \\
\hline L & 60 \\
\hline W & 58 \\
\hline Wp & 18 \\
\hline Lf & 6 \\
\hline Wf & 10 \\
\hline Lo & 0.9 \\
\hline Wo & 5 \\
\hline D1 & 2.35 \\
\hline D2 & 34 \\
\hline Lc & 30 \\
\hline Wc & 8.5 \\
\hline L1 & 3 \\
\hline L2 & 17.5 \\
\hline Lg & 16 \\
\hline Wg & 8 \\
\hline
\end{tabular}


The antenna that have finalized is optimized from the base design shown in Figure 4. The first parameter sweep is performed at $\mathrm{Lp}$ to find the best return loss for the antenna to be able to operate at $2.45 \mathrm{GHz}$. From the simulation result, the best $\mathrm{Lp}$ is at $18 \mathrm{~mm}$. Next, the ring slot at the ground is optimized by varying its inner diameter from 15 to $20 \mathrm{~mm}$ to increase the value of return loss at $1.48,3.63$ and $8.74 \mathrm{GHz}$ to above $-10 \mathrm{~dB}$ to consider they are successfully suppressed and also to improve the return loss of the antenna. The best inner diameter of the ring obtained is $\mathrm{D} 1=30 \mathrm{~mm}$.

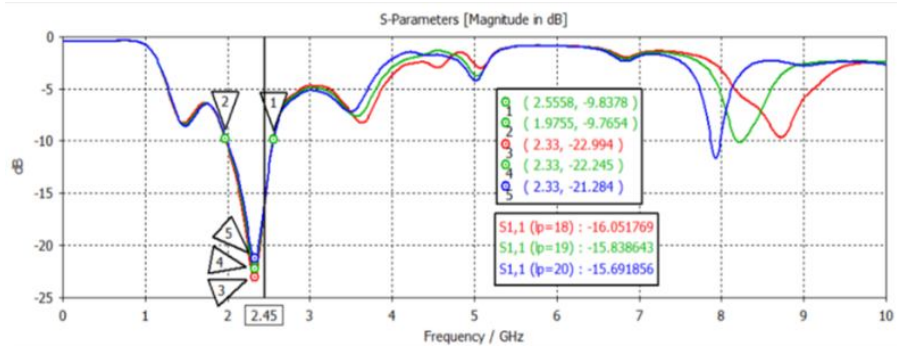

Figure 4: Return Loss Graph with various Lp

Firstly, based on Figure 4 the difference between the return loss graphs is the length of Lp shown in Table 2. The best acquired result is the red one with $\mathrm{Lp}=18 \mathrm{~mm}$. This is because of the value of return loss at resonant frequency and at $2.45 \mathrm{GHz}$ are better than the other two. Besides that, the harmonics are also plotted above $-10 \mathrm{~dB}$ which means that it is suppressed successfully than with the other two higher values of Lp. From the result, it shows that the antenna resonates at $2.33 \mathrm{GHz}$ frequency which is the best result obtained after optimization, to fulfil the required $2.45 \mathrm{GHz}$ resonating frequency as it is still located under the -10db threshold of working frequency.

From the parameter sweep process, the length of Lp is observed to be an important element that affects the antenna resonating frequency. However, after $20 \mathrm{~mm}$ length of $\mathrm{Lp}$, the antenna resonates at above $3 \mathrm{GHz}$ and creates a certain harmonic. Therefore, a parameter sweep is performed from $\mathrm{Lp}=20 \mathrm{~mm}$ until $18 \mathrm{~mm}$, minimum value before other harmonics exists at lower Lp. Therefore, $18 \mathrm{~mm}$ is assumed to be the best length to obtain $2.45 \mathrm{GHz}$ operating frequency.

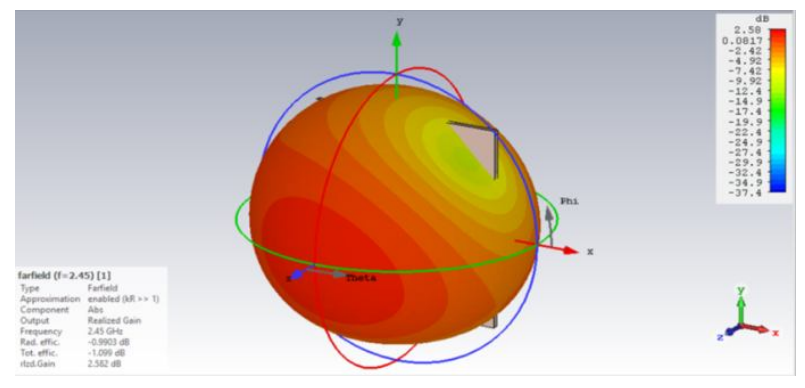

Figure 5: Radiation Pattern

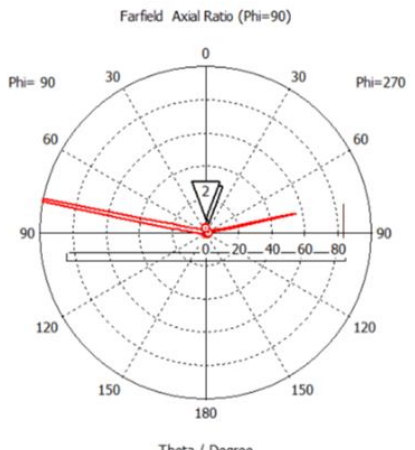

q $(90,1.496)$
q $(0,2.695)$

Theta / Degree

Frequency $=2.45 \mathrm{GHz}$ Man lobe magntude $=\quad 100$

Figure 6: VSWR

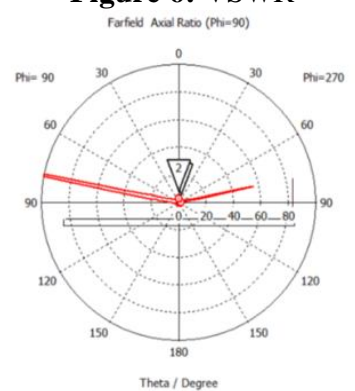

Figure 7: Axial ratio

$\left\{\begin{array}{l}(90,1.496) \\ q(0,2.695)\end{array}\right.$

After various parameter sweep process had been performed, a finalized design is fabricated and measured in the lab. The Figures 5, Figure 6 and Figure 7 below show the radiation pattern, VSWR and axial ratio results obtain from simulation respectively.

The radiation pattern of the antenna shown in Figure 5 shows the shape of the antenna to be omnidirectional. The HPBW radiates at $2.46 \mathrm{~dB}$ magnitude with a direction angle of 174 degree. Next, the gain and VSWR of the antenna in Figure 6 shows that the antenna has a good performance with the value of $2.58 \mathrm{~dB}$ and 1.29 respectively at $2.45 \mathrm{GHz}$ frequency. Axial ratio of antenna shown in Figure 4.4 gives the value within less than $3 \mathrm{~dB}$ threshold that is acceptable to consider it as circular polarized.

The table 3 shows the analysis of the effects of changing various parameter to the performance of the antenna.

Table 3: Parameter Sweep Results

\begin{tabular}{|c|c|c|c|}
\hline \multirow{3}{*}{ Parameter } & $\begin{array}{c}\text { Value } \\
(\mathbf{m m})\end{array}$ & $\begin{array}{c}\text { Resonance } \\
\text { Frequency (Return } \\
\text { Loss in dB) }\end{array}$ & $\begin{array}{c}\text { Axial Ratio } \\
\text { at 2.45GHz } \\
(\mathbf{d B})\end{array}$ \\
\hline \multirow{3}{*}{ Lp } & 18 & $2.33(-23.00)$ & \multirow{2}{*}{$>2$} \\
\cline { 2 - 3 } & 19 & $2.33(-22.25)$ & \\
\cline { 2 - 3 } & 20 & $2.33(-21.28)$ & \multirow{2}{*}{$<3$} \\
\hline \multirow{4}{*}{ D2 } & 26 & $\begin{array}{c}1.38(-11.80) \\
2.30(-13.13)\end{array}$ & $>2$ \\
\cline { 2 - 4 } & 28 & $2.30(-13.01)$ & $>2$ \\
\cline { 2 - 3 } & 30 & $2.33(-23.00)$ & \\
\hline
\end{tabular}


The following figure is the measured return loss that is obtained by using the Vector Network Analyzer (Agilent) that is available in the lab. The graph clearly visualize that the antenna's best radiation is at $2.36 \mathrm{GHz}$ and it works from frequency of 2.00 to 2.56 , giving the total bandwidth is $500 \mathrm{MHz}$. The graph also shows that all the harmonics frequency up to $10 \mathrm{GHz}$ is successfully considering that it is suppressed above -10dB.

\section{CONCLUSION}

The work presented focused on designing a circularly polarized microstrip antenna operating at $2.45 \mathrm{GHz}$ and able to suppress harmonics to increase its efficiency. The paper presented a new design that has been optimized based on a circular ring slot placed on the ground side of a rectangular patch antenna. The first design to consider as the base design, consist of just the circular ring slot. From there, an L-shaped slot unioned with the ring slot to delay the phase at $2.45 \mathrm{GHz}$ and create circular polarization is added. In the final design, two vertical slots placed under the ring slot is introduced to suppress harmonics at higher order frequency. The antenna is designed using parametric study that is defined by varying the measurement of the patch and slots.

In the first objective, the goal to make the antenna operates at $2.45 \mathrm{GHz}$ is reached by altering the length and width of patch, $\mathrm{Lp}$ and $\mathrm{Wp}$. While the antenna behavior to reject harmonics is controlled using the slots on the ground plane which also gone through the same technique. Secondly, the objective to simulate all the designs in CST software had been performed and optimization of the antenna

\section{ACKNOWLEDGEMENT}

The authors gratefully appreciate the great help and useful comments of Editors and reviewers. They would also like to acknowledge the financial support by the Ministry of Education Malaysia and Universiti Teknikal Malaysia Melaka. The work was supported by UTeM under research grants RACER/2019/FKEKK-CETRI/F00406.

\section{REFERENCES}

1 Aaron Don M. Africa, Francis Xavier Asuncion, Raymund Miguel Francisco A. Munchua, Janos Lance Tiberio, Joshua Vincent Ligayo and Raine Mattheus Manuel, "PCB/Microstrip Antenna Design and Simulation," International Journal of Emerging Trends in Engineering Research, vol. 7, no. 8, pp. 157-162, 2019. https://doi.org/10.30534/ijeter/2019/09782019

2 A. Vyas, P. K. Singhal, S. Swarnkar, and T. Srivastava, Soft Computing: Theories and Applications, vol. 742. Springer Singapore, 2019.

3 N. Zainol, Z. Zakaria, M. Abu, and M. Mohamed Yunus, "A 2.45 GHz Harmonic Suppression
Rectangular Patch Antenna with Circular Polarization for Wireless Power Transfer Application," IETE J. Res., vol. 64, no. 3, pp. 310-316, 2018.

$4 \quad \mathrm{H}$. Pal and Y. K. Choukiker, "Design of frequency reconfigurable antenna with ambient RF-energy harvester system," 2016 Int. Conf. Inf. Commun. Embed. Syst. ICICES 2016, 2016.

5 M. S. Khan, B. Ijaz, D. E. Anagnostou, B. D. Braaten, A.-D. Capobianco, and S. Asif, "Frequency reconfigurable self-adapting conformal array for changing surfaces," IET Microwaves, Antennas Propag., vol. 10, no. 8, pp. 897-901, 2016.

https://doi.org/10.1049/iet-map.2015.0622

6 C. Y. D. Sim, W. C. Weng, M. H. Chang, and B. Y. Chen, "Annular-ring slot antenna designs with circular polarization radiation," Int. J. $R F$ Microw. Comput. Eng., vol. 25, no. 4, pp. 337-345, 2015.

7 A. Mohamed, I. M. Rafiqul, S. Yasmin, and K. Badron, "Design of a Quintuple Band Microstrip Patch Antenna Using Multiple L-Slots," Proc. 6th Int. Conf. Comput. Commun. Eng. Innov. Technol. to Serve Humanit. ICCCE 2016, no. mm, pp. 30-35, 2016.

8 Lakshmi Charan Tangisetti, T.V. Rama Krishna and K. Kumar Naik,"A Compact UWB Microstrip Antenna With Hexagonal Circular Patch And Asymmetric CPW-Fed for On-body Applications," International Journal of Emerging Trends in Engineering Research, vol. 8, no. 2, pp. 584-590, 2020.

https://doi.org/10.30534/ijeter/2020/49822020

9 Aaron Don M. Africa, Darlene Alyssa P. Abaluna and Kyle Daniel P. Pimentel, "Monitoring and Control Systems in Agricultural Machineries and Equipment with a Low-Power Smart Antenna System," International Journal of Emerging Trends in Engineering Research, vol. 8, no. 5, pp. 1860-1868, 2020.

10 R. Kumar and A. Saxena, "Elliptical Micro-strip Patch Antenna For Circular Polarization Design Using HFSS," pp. 1408-1411, 2016.

11 P. S. Gaur and V. S. Kushwah, "Design and Analysis of Monopolar Patch Antenna for Ultra Wide-band Application," vol. 6, no. 4, pp. 768-771, 2016.

12 Misran, M.H., Said, M.A.M., Salleh, A., Ramlee, R.A., "Ultra-wideband antenna with Y-shape defected ground structure," International Journal of Emerging Trends in Engineering Research, 2020.

https://doi.org/10.30534/ijeter/2020/116872020

13 W. Li, P. Li, J. Zhou, and Q. H. Liu, "Control of higher order harmonics and spurious modes for microstrip patch antennas," IEEE Access, vol. 6, 
Maizatul Alice Meor Said et al., International Journal of Emerging Trends in Engineering Research, 8(8), August 2020, 4420 - 4425

no. c, pp. 34158-34165, 2018.

https://doi.org/10.1109/ACCESS.2018.2850858

14 M. I. Sabran, S. K. A. Rahim, C. Y. Leow, P. J.

Soh, B. W. Chew, and G. A. E. Vandenbosch,

"Compact circularly polarized truncated square

ring slot antenna with suppressed higher

resonances," PLoS One, vol. 12, no. 2, pp. 1-13,

2017.

https://doi.org/10.1371/journal.pone.0172162 